\title{
QUANTITATIVE ANALYSIS OF FATIGUE FRACTURE SURFACE IN THE DUPLEX STEEL
}

\author{
MARIA SOZAŃSKA ${ }^{1}$, FRANCESCO IACOVIELlO ${ }^{2}$, JAN CWAJNA ${ }^{1}$, MICHEL JEROME ${ }^{3}$, JAROSLAV \\ SOJKA $^{4}$ AND JACQUES GALLAND ${ }^{3}$ \\ ${ }^{1}$ Silesian University of Technology, Krasińskiego 8, 40-019 Katowice, Poland, ${ }^{2}$ Unversita di Cassino, via di \\ Biasio 43, 03043 Cassino, Italy, ${ }^{3}$ Ecole Centrale Paris, 92295 Châtenay-Malabry Cedex, France, ${ }^{4}$ Technical \\ University of Ostrava, 17. Listopadu 15, 70833 Ostrava-Poruba, Czech Republic \\ e-mail:mariasoz@polsl.katowice.pl \\ (Accepted February 26, 2002)
}

\begin{abstract}
We present a quantitative and qualitative analysis of the fatigue surface of Z2CND2205 duplex steel. Both the ferritic and austenitic phases of this duplex steel are investigated. The observed brittleness of the steel is here due to the presence of hydrogen. The hydrogen influence is complex in that the two phases are altered by hydrogen in different ways. Quantitative parameters describing striations spacing in each phase are measured.
\end{abstract}

Keywords: corrosion, duplex steel, fatigue, hydrogen, striation.

\section{INTRODUCTION}

The austenitic-ferritic Z2CND2205 steel is widely used in the chemical, petrochemical and power industry. The steel has a good resistance to corrosion, particularly to stress corrosion whose net effect is damaging. The advantages of both austenitic- and ferritic-steel are combined in this duplex steel. The austenitic phase ensures ductility, and resistance to the corrosive effects of electro-chemical corrosion; the ferritic phase ensures resistance to the stress corrosion. A great deal of work has shown that austenitic-ferritic duplex steels are altered by the presence of hydrogen yielding a decrease of their plastic properties (Nicodemi and Zoja, 1975; Davidson, 1990; Desestret and Charles, 1990). The hydrogen influence is complex because each of the constituting phases - ferrite and austenite- is altered its own way by hydrogen. The ferrite, due to its bodycentered cubic lattice, is a priori more sensitive than the austenite exhibiting a face-centered cubic lattice. However, the sensitivity of austenite to hydrogene may actually increase in response to structural changes after tempering and $\alpha^{\prime}$ (martensite) and $\varepsilon$ (carbide) formation. The brittleness of the austenitic-ferritic steels under hydrogen influence is actually four-fold:

- penetration of the hydrogen into the metal,

- the diffusion of hydrogen in the metal,

- the hydrogen trapping,

- and, the material brittleness.

Herein, one relies on quantitative fractography to evaluate the sensitivity of the Z2CND2205 steel to the degrading influence of hydrogen.

\section{MATERIAL}

The chemical composition of the Z2CND2205 steel and its mechanical properties are listed in table 1 (Iacoviello, 1997). Tensile specimens were taken in two basic directions with respect to the rolling direction (L: longitudinal; T: transversal).

Table 1. Chemical composition (in wt \%) and mechanical properties of Z2CND2205 steel.

\begin{tabular}{|c|c|c|c|c|c|c|c|c|}
\hline $\mathrm{C}$ & $\mathrm{Si}$ & Mn & $\mathrm{P}$ & $\mathrm{S}$ & $\mathrm{Cr}$ & $\mathrm{Ni}$ & Mo & $\mathrm{N}$ \\
\hline 0.019 & 0.39 & 1.51 & 0.022 & 0.002 & 22.45 & 5.50 & 3.12 & 0.169 \\
\hline Direction & & Y.S. [MPa] & & U.T.S. [MPa] & & $\mathrm{A}[\%]$ & & $\mathrm{J}_{\mathrm{IC}}\left[\mathrm{kJ} / \mathrm{m}^{2}\right]$ \\
\hline $\mathrm{T}$ & & 565 & & 827 & & 35 & & 140 (TL) \\
\hline $\mathrm{L}$ & & 513 & & 790 & & 39 & & 200 (LT) \\
\hline
\end{tabular}

Y.S. (Yield Stress), U.T.S. (Ultimate Tensile Stress), A (Strain of 0.5\%), J IC (critical J value). 
The Z2CND2205, also referred to as the "Uranus $45 \mathrm{~N}$ " steel (trade name), was quenched in water at $1050^{\circ} \mathrm{C}$. Its fine-grain microstructure is characterised by streaked bands, with ferritic islands embedded in an austenitic matrix. X-ray diffraction revealed a ferritic phase content of about $55.4 \%$. The specimens for the strength tests were tempered during three hours at $475^{\circ} \mathrm{C}$ in an argon atmosphere, and then cooled in water. The amount of hydrogen was determined by degassing under vacuum $\left(10^{-3} \mathrm{~Pa}\right)$ at $600^{\circ} \mathrm{C}$ during $20 \mathrm{~min}$. The measured amount of hydrogen was 110 ppm (Boniardi et al., 1996).

\section{FATIGUE TESTS}

During the fatigue tests of the Z2CND2205 steel, the da/dN cracking rate was measured as a function of $\Delta \mathrm{K}$, the stress intensity range, under the following conditions:

- Compact type (CT) specimens ASTM E674, type LT and TL (the first letter denotes the direction of the applied load, the second letter denotes the direction of crack growth),

- in air, temperature $20^{\circ} \mathrm{C}$, frequency: $1,10,20 \mathrm{~Hz}$,

- in a corrosive medium, temperature $20^{\circ} \mathrm{C}, 1 \mathrm{~N}$ $\mathrm{H}_{2} \mathrm{SO}_{4}$ aqueous solution, frequency: $1,10,20 \mathrm{~Hz}$,

- the tests were performed using a sinusoidal force

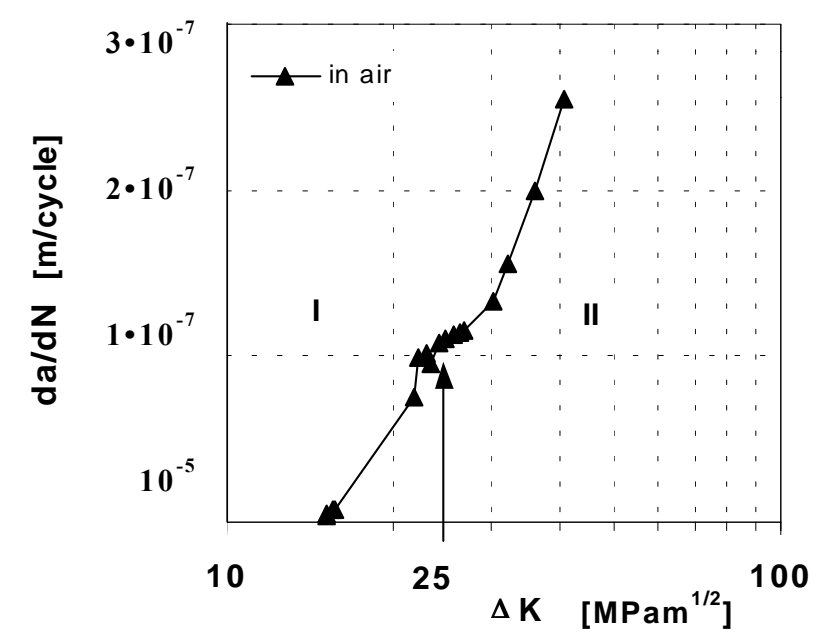

with $\mathrm{R}=\mathrm{K}_{\min } / \mathrm{K}_{\max }=0.1$ constant.

Generally the cracking evolution rate as a function of the stress intensity range, is given by the Paris' relation:

$$
\mathrm{da} / \mathrm{dN}=\mathrm{C} \Delta \mathrm{K}^{\mathrm{m}}
$$

where: $\mathrm{da} / \mathrm{dN}$ - cracking rate $[\mathrm{mm} /$ cycle], a - crack length, $\mathrm{N}$-number of cycle,

$\mathrm{C}$ - constant depending on the material,

$\mathrm{m}$ - constant depending on the material and cyclic stresses,

$\Delta \mathrm{K}$ - stress intensity range $\left[\mathrm{MPa} \mathrm{m}^{1 / 2}\right]$.

Fig. 1 shows examples of da/dN cracking rates as a function of $\Delta \mathrm{K}$ (stress intensity range) measured in air, and in a corrosive environment (Iacoviello et al., 1997). In Fig. 1, the cracking rate is not given by the single Paris' relation but consists of several segments with different coefficient $\mathrm{m}$. For the tests in air, the cracking curve shows two segments: a first segment for $\Delta \mathrm{K} \leq 22 \mathrm{MPa} \mathrm{m}{ }^{1 / 2}$ and, a second for $\Delta \mathrm{K}>22 \mathrm{MPa}$ $\mathrm{m}^{1 / 2}$. An increase in the cracking rate is observed in the $\mathrm{H}_{2} \mathrm{SO}_{4}$ solution. The cracking curve in the corrosive medium shows three segments: a first one for $\Delta \mathrm{K} \leq 25 \mathrm{MPa} \mathrm{m}^{1 / 2}$, a second one for $25 \mathrm{MPa} \mathrm{m}{ }^{1 / 2} \leq \Delta \mathrm{K} \leq 55 \mathrm{MPa} \mathrm{m}^{1 / 2}$ and, a third one for $\Delta \mathrm{K}>55 \mathrm{MPa} \mathrm{m}^{1 / 2}$.

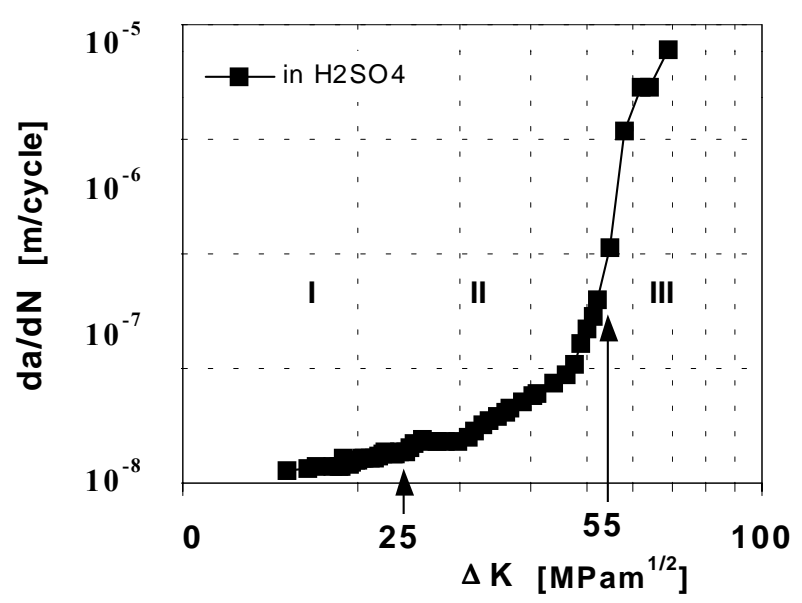

Fig. 1. Cracking rate da/dN as a function of the $\Delta K$ stress intensity range in air and in $\mathrm{H}_{2} \mathrm{SO}_{4}$ solution (region I: non-continuum mechanisms, region II: continuum mechanisms (striation growth), region III: final failure). 


\section{FRACTOGRAPHIC ANALYSIS}

\section{Fractures in air}

In the case of cracking in air, the fractographic examination shows the formation of ductile striations both in the ferrite $(\alpha)$ and austenite $(\gamma)$ phases (Fig. 2).

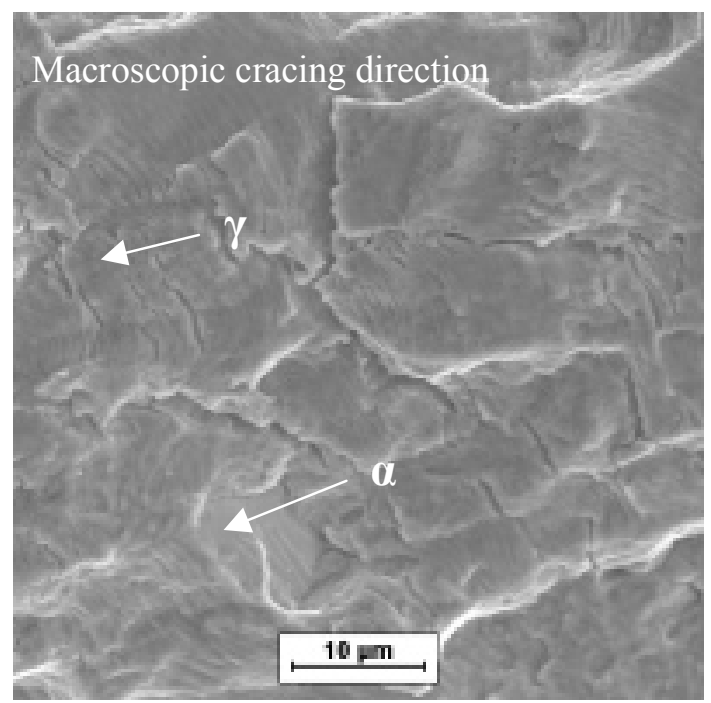

Fig. 2. Fatigue striations after the tests in air.

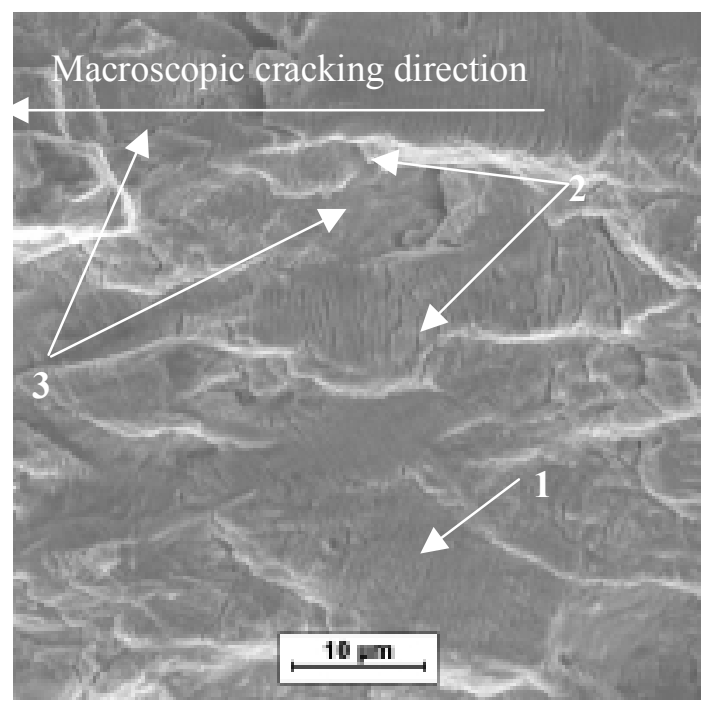

Fig. 3. Fatigue striations after the tests in $\mathrm{H}_{2} \mathrm{SO}_{4}$.

The fatigue striations are not perpendicular to the macroscopic cracking direction and secondary cracks are strongly inclined with respect to the macroscopic cracking direction, particularly at small $\Delta \mathrm{K}$. As $\Delta \mathrm{K}$ increases, the fatigue striations become more perpendicular to the macroscopic cracking direction.

\section{Fractures in a corrosive medium}

In the case of cracking in a corrosive environment $\left(\mathrm{H}_{2} \mathrm{SO}_{4}\right)$, the formation of striations happens both in the ferrite and austenite (Fig. 3) and a higher cracking rate is obtained. The detailed examination of the fatigue fracture surfaces reveals that the ferritic phase brittleness is due to hydrogen (Shiquiong et al., 1989; Dickson et al., 1990). In the first range of the $\log (\mathrm{da} / \mathrm{dN})=\mathrm{f}(\log \Delta \mathrm{K})$ cracking curve, fatigue striations are brittle in the ferrite (Fig. 3, point 1). The river patterns are parallel to the macroscopic cracking direction (Fig. 3, point 2). Numerous secondary cracks are present at the austenite-ferrite boundary and they are not perpendicular to the cracking direction (Fig. 3 and Fig. 4, point 3). In the second range of the cracking curve, the fracture is brittle in the ferrite as revealed by the presence of the "leaf structure" (Fig. 4, point 4) and characteristic "triangles" (Fig. 5, point 5). The river patterns are not parallel to the cracking direction. Based on the corrosion figures, the cracking plane in the ferrite is of type [100] (Dickson et al., 1990). For higher cracking rates the fatigue striations are of the ductile type both in the ferrite and austenite and they are perpendicular to the cracking direction.

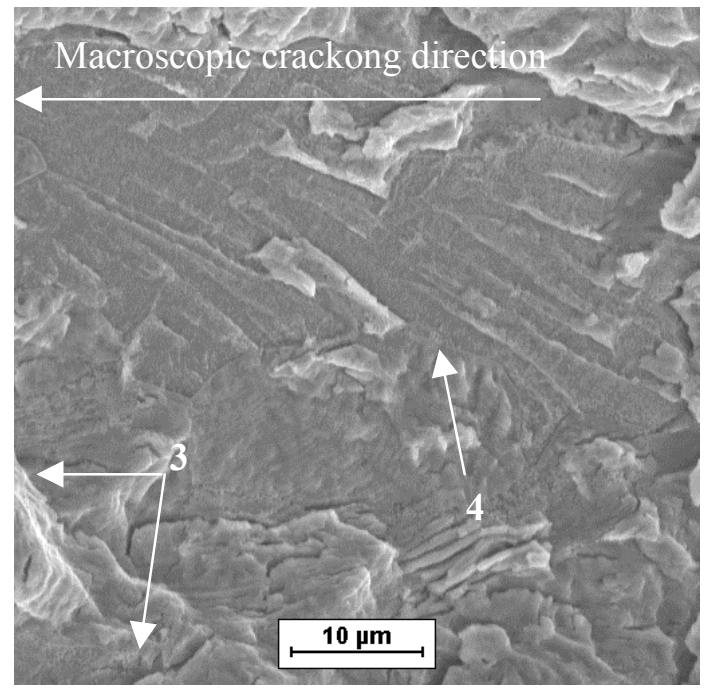

Fig. 4. "Leaf structure" after the tests in $\mathrm{H}_{2} \mathrm{SO}_{4}$.

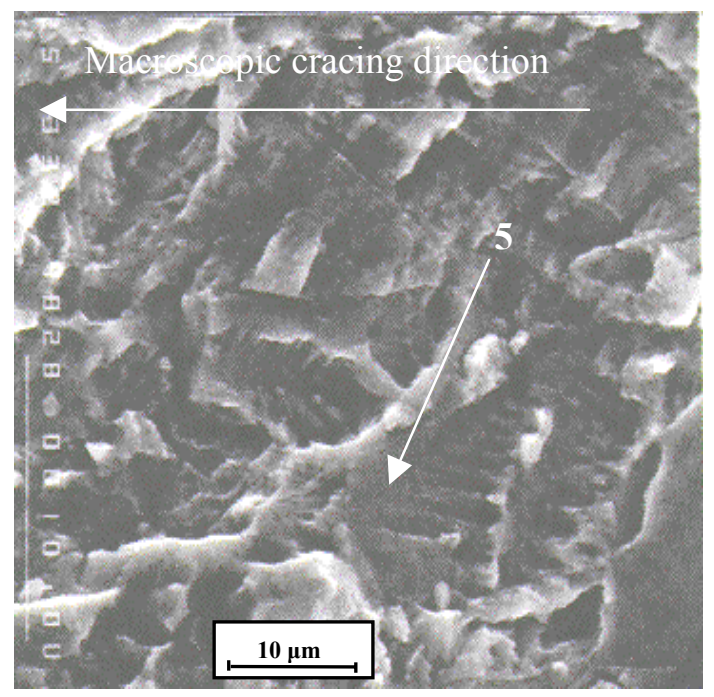

Fig. 5. "Triangles" after the tests in $\mathrm{H}_{2} \mathrm{SO}_{4}$. 


\section{STRIATION SPACING}

A correlation exists between the progress of fatigue cracking and fatigue striation spacing. The measurement of the striation spacing is accordingly important and can be a basic parameter used in the further studies. The above assumption is valid in cases when the macroscopic speed of cracking is controlled by propagation mode (Kocańda, 1985). We can find the projected striation spacing by counting striations number per unit of projected length (Chermant and Coster, 1979):

$$
\mathrm{N}_{\mathrm{L}}^{\prime}=\mathrm{N}_{\mathrm{S}} / \mathrm{L},
$$

$\mathrm{N}_{\mathrm{S}}$ - number of striations,

L' - projected length.

Mean projected distance between 2 striations is then:

$$
\overline{\mathrm{d}^{\prime}}=1 / \mathrm{N}^{\prime} \text {. }
$$

The measurement can be quickly made on a set of parallels (Underwood and Stark, 1979). Yet, because the local orientation of the striations is neglected, the resulting striation spacing would be overestimated (Coster and Chermant, 1983). If the locally parallel striations are oriented randomly with respect to the macroscopic cracking direction (Coster and Chermant, $1983)$ then, the correct projected spacing is expressed by:

$$
{\overline{\mathrm{d}^{\prime}}}_{\text {corrected }}=2 / \pi \overline{\mathrm{d}}^{\prime} .
$$

Finally N'${ }_{\mathrm{L}}$ (Eq. 2) being measured on a projected plane, it must be corrected according to Eq. 5:

$$
\mathrm{N}_{\mathrm{L}}=\mathrm{N}_{\mathrm{L}}^{\prime} / \mathrm{R}_{\mathrm{L}}
$$

where $R_{L}$ is the linear roughness index of the profile line.

Here, as in Nieh and Nix (1980), it is assumed that the fracture surface is perpendicular to the beam of electrons so that no roughness correction of type Eq. 5 is needed. The striation spacing can be obtained from the screen of the scanning microscope. A sample was carefully positioned to ensure that the beam of electrons was locally perpendicular to the fracture surface carrying the striations. Differences of grey level obtained in microscopic image were analysed by the VISILOG software. A striation spacing was measured for each group of locally parallel striations. An example of measurement is showed in Fig. 6.

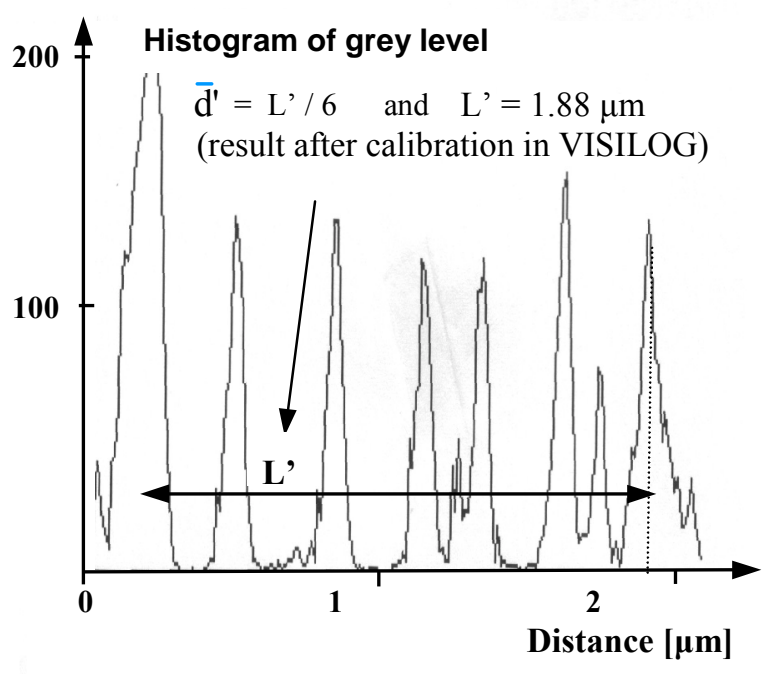

Fig. 6. Measurement of $\overline{\mathrm{d}}_{\text {corrected }}$ striation spacing on histogram.

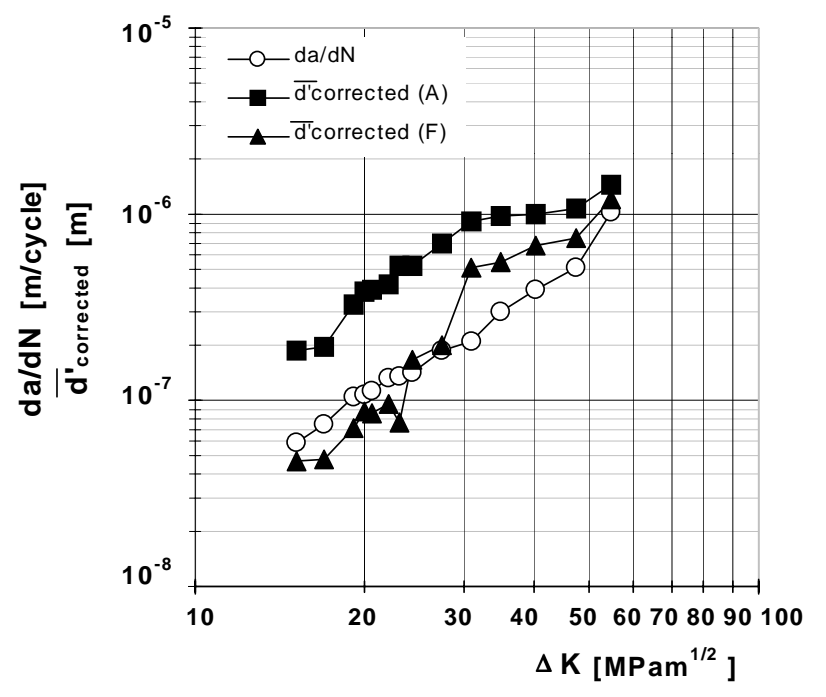

Fig.7. Striation spacing $\overline{\mathrm{d}}_{\text {corrected }}\left(\overline{\mathrm{d}}_{\text {corrected }}(A)\right.$ in austenite, $\overline{\mathrm{d}}_{\text {corrected }}(F)$ in ferrite) and $\mathbf{d a} / \mathbf{d} \mathbf{N}$ cracking rate as function of the $\boldsymbol{\Delta K}$ stress intensity range in $\mathrm{H}_{2} \mathrm{SO}_{4}$ solution.

Our results show that the striation spacing depends on the size of cracking a, as well as on stress intensity factor value $\Delta \mathbf{K}$ (Fig. 7). Such a results allow to describe the influence of hydrogen on the cracking process in the duplex steel by fractography methods. The striation spacing in the ferrite and in the austenite are described separately. In air, the striation spacing in the ferrite is equal to the striation spacing in the austenite. In the presence of hydrogen, the striation spacing in the ferrite is smaller than in the austenite. 
This result can be explained by the different speeds of transport of hydrogen in the ferrite and in the austenite. The crystallography of the ferrite fracture in the $\mathrm{H}_{2} \mathrm{SO}_{4}$ solution is the first elementary argument favouring the hydrogen embrittlement theory (Kikuta et al., 1975). The presence of twins, enhancing initially local plasticity and local plastic deformation, which are formed on the cracking front and allow a local change of the cracking direction, shows in accordance with the Bastien's theory, that hydrogen is the reason for cracking. The difference of appearance of the fracture at the middle and the edges of the specimen in the ferrite, is the second argument: at the middle of the specimen, a brittle fracture zone occurs but at the edges there are ductile fatigue striations. This result is consistent with the tendency of the atomic hydrogen to diffuse towards areas with strong hydrostatic stress, characterising the state of the plane deformation, which is achieved in the centre of the specimen. The width of this zone on the corrosive medium increases if $\Delta \mathrm{K}$ increases. It is consistent quantitatively with an increase in the width of the edge zone subjected to the plane stress state which corresponds to an increase in $\Delta \mathrm{K}$.

\section{CONCLUSION}

Our analysis of fatigue surfaces shows that the fatigue fracture of the austenite phase forms in a ductile way in air and in the $\mathrm{H}_{2} \mathrm{SO}_{4}$ solution. The austenite presence causes a decrease in the macroscopic cracking rate of the duplex steel. The hydrogen embrittlement theory is the basic theory that explains the effect of cracking rate increase. The results of the striation spacing study together with fractographic analyses give valuable information about hydrogen interaction in ferrite and in austenite in duplex steels.

\section{ACKNOWLEDGEMENT}

This publication is based on the work sponsored by the State Committee for Scientific Research in Poland (project 7T08A 03016 at Silesian University of Technology in Katowice), by Universita di Cassino in Italy and by Ecole Centrale Paris in France.

\section{REFERENCES}

Boniardi M, Iacoviello F, La Vecchia GM, Sozanska M (1996). Analisi della superficie di fratture a fatica nell'acciaio inossdabile bifasico austeno-ferritico 22 $\mathrm{Cr}$ 5Ni. IGF12-XII Convegno Nazionale Gruppo Italiano Frattura. Parma: Italy, 32-42.

Coster M, Chermant J-L (1983). Recent development in quantitative fractography. International Metals Reviews 28(4):228-50.

Chermant J-L, Coster M (1979). Progrès dans les méthodes d'investaigation des matériaux. Cercle d'Etudes des Metaux, Tome XIV, VII:1-14.

Davidson RM (1990). Practical guide to using duplex stainless steels. Materials Performance, 57-65.

Desestret A, Charles J (1990). Les aciers inoxydables austeno-ferritiques, Acier Inoxydables. Paris: Les Editions de Physique, 631.

Dickson JI, Li SA, Bailon JP (1990). Aspects fractographiques de la corrosion sous contrainte, «Corrosion sous contrainte, phénoménologie et mécanismes». Desjardins D, Oltra R, eds. Bombannes, 425-64.

Iacoviello F (1997). Fragilisation par l'hydrogène de l'acier inoxydable austéno-ferritique Z2CND2205: rôle des traitements thermiques de revenu. Thesis Ecole Centrale, Paris, 101-20.

Iacoviello F, Sozańska M, Galland J (1997). Morfologia della superficie de fratture a fatica dell'acciaio inossidabile duplex $22 \mathrm{Cr} 5$ in presenza di indrogeno. IGF 13-XIII Convegno Nazionale Gruppo Italiano Frattura, 1997 May 27-28; Cassino: Italy, 13-20.

Kikuta Y, Araki T, Kuroda T (1975). Fracture morphology of hydrogen embrittlement in steel. Met Trans A271(1281):69-82.

Kocańda S (1985). Zmęczeniowe pękanie metali, Warszawa: WNT, 237-82.

Nicodemi W, Zoja R (1975). Metallurgia applicata. Milano: Taburini Editore, 487.

Nieh TG, Nix WD (1980). Scripta Metallurgica, 14:365.

Shiquiong Li, Dickson JI, Bailon JP (1989). The influence of the stress intensity factor on the fractography of stress corrosion cracking of 316 stainless steel. Mat Sci and Ing A119:59-72.

Underwood EE, Starke EA (1979). ASTM-STP, 675: 633. 